\title{
MODERN TECHNOLOGIES IN FOREIGN LANGUAGE TEACHING: THE CASE OF L.N. GUMILYOV EURASIAN NATIONAL UNIVERSITY
}

\author{
Akzhan Abdykhalykova \\ L.N. Gumilyov Eurasian National University, Nur-Sultan, Kazakhstan, akzhan80@mail.ru
}

\begin{abstract}
Research purpose. The teacher of higher education should motivate students to use modern information technology training to study the discipline and develop professional competencies in foreign language teaching. The purpose of this research is to highlight the problem of finding the optimal didactic capabilities of modern information technologies used for improving the system of training specialists in the field of foreign languages teaching and to discuss the results of current studies in this direction.

Design/Methodology/Approach. The authors summarized the relevant literature and results of the research and teaching experience. The main theoretical methods of research are modelling and designing the process of incorporating modern information technologies into foreign language teaching at the university. Theoretical methods are supplemented by empirical methods, such as observation, survey, testing, experimental work and methodological analysis.
\end{abstract}

Findings. The article reveals the main components of the system of using modern technologies of foreign languages teaching at Theory and Practice of Foreign Languages Department of L.N. Gumilyov Eurasian National University. The article presents a description of training and monitoring online programs, their approbation in real conditions of pedagogical activity, the results of a pedagogical experiment, which proves the effectiveness of using modern technologies in the training of foreign and second language students.

Originality/Value/Practical implications. The electronic educational materials, recommendations developed by the authors, can be used in the teaching of foreign language and can serve as a basis for the development of information, communication and instrumental provision in other subjects. The need for further research is as follows: to create online platforms, multimedia and testing programs and to develop variants of using modern technologies in foreign language teaching.

Keywords: modern technologies; foreign language teaching; multimedia technology; online platform; testing program.

\section{Introduction}

Because of scientific and technological progress, the use of new technologies in various spheres of human activity imposes new requirements for the training of future specialists in the condition of informatization of education.

At the present stage of development of education, Kazakhstan higher school faces the task of improving the quality of training, which with the introduction of new state educational standards (both for undergraduate and graduate) is associated with the prospect of implementing a technological approach to learning science-based new pedagogical and information technologies. In this regard, the purpose of the study is to teach future teachers the ability to competently work with various kinds of information, to make the most of the opportunities of modern information technologies for professional improvement in the field of teaching foreign languages. Implementation of the technological approach in the preparation of the future teacher of English is hampered by the following contradictions:

- Between the rapidly growing level of development of Kazakhstan's information society and the ability of the higher education system to meet the growing requirements 
- Between the need to improve the professional training of future teachers of foreign languages on the basis of technological approach and the weak readiness of university teachers.

- Between the broad didactic possibilities of ICT and the low level of their use in the practice of education at the university.

The following questions arise from the identified contradictions:

- Whether the existing system of professional training of future teachers of foreign languages is capable of providing formation of professional competences which meet new requirements.

- What should the training of future specialists in the field of foreign languages at the university be, so that they can continue to work competently with information and effectively use as well as be able to develop multimedia technologies in their activities?

These issues together defined the problem of the research, which is to improve the system of teaching disciplines on the methodology of teaching foreign languages at the university through information and communication technologies and their instrumental support. Referring to the analysis of the initial facts, contradictions and the problem, we highlight the following main idea of our research: the ability to navigate the ever-increasing volume of information, to use it correctly for various purposes, to use modern means of communication that should become essential components of the modern content of pedagogical education and a computer - a tool for managing the educational process.

\section{Literature Review}

According to Abbas Pourhosein Gilakjani (2017), the use of technology helps learners to get involved and learn based on their interests. It has been extensively accepted for teaching English in the modern world. Technology satisfies both visual and auditory senses of the learners (Solanki \& Shyamleel, 2012). Kimwise and Mugabirwe (2018) opined that several studies in the whole world have shown that the appropriate use of multimedia technology in educational context would provide quite a lot of benefits.

Friggard (2002), Miner (2004) and Timucin (2006) confirmed that technology increases the development of teaching methods and learners' knowledge. Lam and Lawrence [6] also expressed that technology helps learners to regulate their own learning process and have access to any information that their teachers cannot provide. Gilakjani (2013) elaborated that the unique opportunities technologies provide have brought about new tools, approaches and strategies in the teaching and learning of language skills. Technologies are increasingly widespread, impacting many aspects of our social and work lives and many of our leisure activities. Many researchers stated that technology can be used as an instructional tool in teaching and learning skills. Bruce and Levin (2001) expressed that technology can be useful in the classroom by helping communication, making teaching products and assisting learners' self-expression. According to Gilakjani (2017), when we talk about instruction, education or training issues we have to consider the important role of technology. The researchers continued that the application of technologies in education opens a new area of knowledge and provides a tool that has a great potential to change the existing teaching methods.

The use of computer in teaching a foreign language is not limited to classroom activities. Various researchers offer options for the use of Internet technologies in the classroom and in extracurricular work of students. For example, the use of ICT in teaching foreign languages is considered in the works of Russian and Kazakh scientists such as Artykbayeva (2014), Nurgalieva (2002), Kapezovich and Toktarbekovna (2014) and Myamesheva (2015).

A promising direction in the study is the use of Internet technologies, various aspects of which are devoted to many publications. In recent years, teachers have been attracted to the mass open online courses (MOOC) as a new form of online education, since they allow anyone to learn practical training, regardless of time and location.

The question of formation of the content of foreign language teaching methods in universities has received plenty of attention from scientists. On the scope of application of ICT in teaching foreign 
languages, scientists such as Kunanbayeva (2000), Rogova et al. (1991), Zhusubalieva (1977) and Popov (1987) have made a great contribution to teaching English.

However, in our opinion, to date, the impact of online learning on the quality of education has been insufficiently studied. We also tried to work with students online, but at the moment we have not received enough results to mention this direction in the article. The analysis of literature and educational practice has allowed to conclude that in the conditions of fast growth of the volume of information, the computer can become the tool of management of the educational process. New information technologies do not displace the traditional system of education and innovative pedagogical technologies, but complement and strengthen each other. It is an integration process that requires further research to improve the quality of training of the future teacher of a foreign language.

\section{Methodology}

In the process of research the following methods were used: theoretical (analysis of pedagogical, psychological, methodical literature, normative and program - methodical documentation, Internet resources; generalization; forecasting, design and modelling), diagnostic (questioning, testing), empirical (pedagogical observation), experimental (pedagogical experiment) and methods of graphic representation of results.

The experimental base of the research was L.N. Gumilyov Eurasian National University, Philology Faculty, Theory and Practice of Foreign Languages Department, Specialty 'Foreign languages: two foreign languages'.

The problem was studied in three stages. In the first stage, a theoretical analysis of the existing methodological approaches in the psychological, pedagogical, methodical scientific literature and dissertations on the research topic was carried out; the problem, idea, purpose and methods of research were identified; the plan of the experimental research was drawn up. In the second stage, an information system of foreign language teaching was developed; a set of components of this system was identified and justified for the effective training of the future teacher of foreign languages. In the third stage, experimental work was carried out, analysed and tested; and refined insights obtained in the course of the pedagogical experiment were summarized and the obtained results reported.

\section{Results}

In the first stage of theoretical analysis of the existing methodological approaches to teaching a foreign language, the aim was to develop students' ability to understand the process of developing online technologies. Although the needs of the analysis have become an important stage in the development of a foreign language for professional purposes, the analysis has mainly provided information on what to teach, leaving unanswered the question of how to teach. Systematization of previous experience has led to the fact that the students' needs were in the centre of attention of developers of foreign language programs for professional purposes. This approach was called personality-oriented (learning-centred approach), in which the centre is the personality of the student and his cognitive activity, and the students' needs are the basis for the construction of the course.

Information technologies open up new opportunities for the future teacher of foreign languages and form a new way of thinking and action laying the foundations of new ethics and culture of understanding of the world. The basis of information technology of foreign language learning is computer training, the successful implementation of which (in addition to the computer as the main technical means) requires special didactic tools and thoughtful methods of working with them.

In the second stage, students developed multimedia products for teaching and learning English. This work was carried out by us in the following areas:

- Creation of electronic learning platforms, blogs that can be used as a means of visibility, submission and receiving of information, control of knowledge and skills, creative activity, etc.

- Creation of training and test programs, which can then be supplemented and improved by the students themselves. 
In this article, we present the introduction of multimedia technologies in foreign languages teaching. Table 1 is a brief description of multimedia products that we use in our teaching process.

\section{Table 1. A brief description of multimedia products}

\begin{tabular}{|c|c|}
\hline $\begin{array}{l}\text { Electronic } \\
\text { textbook, } \\
\text { multimedia } \\
\text { teaching materials } \\
\text { of disciplines }\end{array}$ & $\begin{array}{l}\text { A software tool designed to facilitate an active understanding and memorization using the } \\
\text { computer in learning process involving aural and emotional memory. It is not only text } \\
\text { information as such, but the whole technology of information delivery to the consumer, } \\
\text { namely, multimedia components; interactive elements; controls; powerful search engine; } \\
\text { hypertext link system; additional service capabilities (bookmarks, notes, filing, etc.); } \\
\text { opportunity for comfortable reading; synchronous listening and a host of other things } \\
\text { (Thamarana, 2015) } \\
\text { Electronic textbook and multimedia teaching materials of disciplines as software for } \\
\text { educational purposes can be represented as a system consisting of two subsystems: } \\
\text { information (substantial part) and software (software). Informational part of the electronic } \\
\text { textbook and multimedia teaching materials of disciplines may include well-structured } \\
\text { training materials, multimedia illustrations, practical works with assignment examples and } \\
\text { analysis of common errors, diagnostic and control system, methodological } \\
\text { recommendations on the study of the course, additional materials, services (assistance, } \\
\text { dictionary, etc.), information about the authors. The software part of the electronic } \\
\text { textbook may include registration system, modules of educational materials, } \\
\text { supplementary materials, the communication system (liaison between teacher and } \\
\text { students), the service (help, dictionary, search system) and the protection system. }\end{array}$ \\
\hline $\begin{array}{l}\text { Multimedia } \\
\text { encyclopaedia, } \\
\text { multimedia } \\
\text { lectures }\end{array}$ & $\begin{array}{l}\text { The modern educational tool that combines the advantages of different multimedia } \\
\text { technologies and facilitates the perception of even the heaviest educational material. } \\
\text { Unlike traditional encyclopaedia or lectures, multimedia encyclopaedia and lectures can } \\
\text { contain not only text and graphics, but also video and audio recordings, three-dimensional } \\
\text { diagrams, drawings and much more (Young \& Bush, 2004) }\end{array}$ \\
\hline $\begin{array}{l}\text { Electronic } \\
\text { didactic aids }\end{array}$ & $\begin{array}{l}\text { Visualized material, revealing the action or process necessary for a teacher to explain } \\
\text { students the new teaching material; animated historical and geographical maps, electronic } \\
\text { laboratory works and others (Thamarana, 2016) }\end{array}$ \\
\hline Film about events & $\begin{array}{l}\text { A film about important events: video congratulation, corporate celebration, anniversary, } \\
\text { assigning categories, titles, awards, association or expansion, launching of a new product } \\
\text { or production resources, opening new sites, etc. (Motteram, 2015) }\end{array}$ \\
\hline Presentation film & $\begin{array}{l}\text { A film about the activity area of educational institutions and companies offering products } \\
\text { of exceptional quality, service, promotions, discounts, classic and original forms of } \\
\text { services, guarantees and other features. }\end{array}$ \\
\hline $\begin{array}{l}\text { Representative } \\
\text { films }\end{array}$ & $\begin{array}{l}\text { The history of educational institutions, businesses, the main activities, a description of } \\
\text { resources and processes, achievements, prospects, staff, goods, services, partners, covered } \\
\text { market segments, etc. }\end{array}$ \\
\hline Video showcase & $\begin{array}{l}\text { Video sequence to show in a shopping centre or showroom. Video showcase is } \\
\text { successfully used in combination with other videos (video clips, movies, etc.) (Kennedy \& } \\
\text { Soifer, 2017) }\end{array}$ \\
\hline Video catalogue & $\begin{array}{l}\text { Video catalogue of products and services of a company providing information on the } \\
\text { competitive advantages of quantitative and qualitative characteristics of each item. } \\
\text { Efficiency can be improved by combining the video catalogue with other videos. }\end{array}$ \\
\hline $\begin{array}{l}\text { Educational video } \\
\text { film }\end{array}$ & $\begin{array}{l}\text { Didactic videos which a teacher can use in the classroom to explain new educational } \\
\text { material or to enhance students' learning. }\end{array}$ \\
\hline $\begin{array}{l}\text { Digitalization of } \\
\text { books }\end{array}$ & Conversion of paper sources into electronic (digital) type (Healey et al., 2008) \\
\hline Electronic library & $\begin{array}{l}\text { The information system that allows safe and effective use of various collections of } \\
\text { electronic documents (text, image, sound, video, etc.), localized in the system, and } \\
\text { inaccessible communicational networks as well (Kobysia et al., 2017). }\end{array}$ \\
\hline
\end{tabular}


Here we may emphasize the following advantages of multimedia products:

1. Teaching goes faster and knowledge acquisition is deeper, if a student takes a great interest in the subject.

2. Learning the ways of finding correct answers is more important for a student than just learning the answers themselves. That is, learning is more effective if the forms of the acquisition of knowledge and skills are such that they can easily be transferred to real life conditions (which they are designed for).

3. Teaching goes faster if students 'learn the result' of each of their answers immediately. If the answer is correct, then the students should immediately receive confirmation that they did well; if not, they learn about it quickly as well. Even a little delay in getting the results dramatically slows down the learning process. Oftentimes our students have to wait long for the results of their tasks in traditional learning.

4. Being aware of the results of tasks stimulates the completion of upcoming tasks. The difficulties that students have to overcome should appear before them one by one. And the successful solution of these problems has a positive influence on motivating and activating students to learn.

5. Teaching goes faster if the subject program is organized according to the principle of sequential complexity of educational material. The difficulty level of educational material is increasing on a daily basis. This will continue until the desired degree of proficiency and competency is reached (Nayef, 2015).

The use of new tools has significantly transformed the traditional scheme of organization of the process of training, ensuring the development and implementation in practice of the variable structure of the educational process of higher education with components that allow automating many processes.

New technology tools that we use in our teaching process are as follows:

- $\quad$ Speech tools for teachers: Announcify, Chrome Speak, DSpeech, FoxVox, PowerTalk

- $\quad$ Digital storytelling tools: Animoto, Capzles, Cartoonist, PicLits, Pixton

- $\quad$ Podcast tools: Audacity, Easypodcast, PodOmatic, SoundCloud, VozMe

- $\quad$ Survey, polls and quizzes tools: addpoll, Google Forms, Pollhost, Wufoo

- $\quad$ Exercise and testing tools: Kahoot, Socrative, Hot Potatoes

- $\quad$ Online teaching platforms: Padlet, Blog, Nicenet, Canvas, etc.

The use of various technologies allows implementing a differentiated approach to students by creating conditions for their independent work. A methodically well-constructed online material helps to replace the means of paper visibility, frees the teacher from writing on the board and allows one to trace the material of the lesson in dynamics.

The great advantage of using technologies in comparison with traditional means of visualization is the convenience of their storage and distribution with the ability to copy and edit. Colourful on-screen training material increases the interest and motivation of students to learn.

According to the method of using technology in teaching foreign languages, we implement three models of classes:

1. In demo mode (one computer on the teacher's desk + projector)

2. In the individual mode (occupation in a computer class without access to the Internet)

3. In individual remote mode (class in the computer room with Internet access)

To obtain relevant information, it is necessary to develop students' skills of searching for it in a constantly updated resource - the Internet. To do this, students are offered our catalogues of public sites and various online tools. 
In the third stage, the experimental work was carried out to identify the impact of multimedia technologies on the academic performance of students. The study was conducted in two groups, one experimental and the other control; each group had 25 students. Both groups were equivalent in the direction of training, academic performance and teaching program. In the first group (experimental) multimedia technologies were used in the educational process, and in the second group (control) the educational process was organized by the traditional method. The study was conducted during one semester. After the final testing of the level of performance, the results of the study were processed and analysed. When processing the results, a test was used to check the differences between the control and experimental groups. The analysis of the results of the final testing showed that there are statistically significant differences between the experimental and control groups; the statistical significance level was $47 \%$. The best indicators of academic performance in the experimental group compared to the control group were noted, which emphasizes the contribution of multimedia technologies to the learning process.

\section{Conclusions}

In recent years, new technologies have had a significant impact on the improvement of the education system and have been an important focus of the restructuring of both general and higher education. The main educational value of information technologies is that they allow creating a multisensory interactive learning environment with almost unlimited potential opportunities, which appear in the teaching and learning environment. In contrast to the technical means of education, information technology allows not only to saturate teaching with a large amount of knowledge, but also to develop the intellectual and creative abilities of students, their ability to acquire new knowledge as well as to work with various sources of information. Using the above information, educational technology for teaching foreign languages helps to increase motivation to study a particular discipline, deeper assimilation of the material, the development of skills of search, analysis and structuring of information and, ultimately, the formation of general cultural and professional competencies defined in modern state educational institutions of higher education. The materials of this article may be of use for teachers engaged in the training of specialists in the field of foreign languages, as well as students of higher educational institutions. In conclusion, this article was designed for teachers who mainly adhere to traditional and outdated methods, whereas they are virtually not sophisticated in using modern devices, applications and sources in teaching.

\section{References}

Artykbayeva, E.V. (2014). Theory and Technology of E-Learning in Secondary School. Synopsis of a Thesis, Almaty.

Bruce, B., \& Levin, J. (2001). Roles for new technologies in language arts: Inquiry, communication, construction, and expression. In J. Jenson, J. Flood, D. Lapp, \& J. Squire (Eds.), The handbook for research on teaching the language arts. NY: Macmillan.

Frigaard, A. (2002). Does the computer lab improve student performance on vocabulary, grammar, and listening comprehension? ERIC Document Reproduction Service No. ED476749

Gilakjani, A. P. (2013). Factors contributing to teachers' use of computer technology in the classroom. Universal Journal of Educational Research, 1(3), 262-267.

Gilakjani, A. P. (2017). A Review of the Literature on the Integration of Technology into the Learning and Teaching of English Language Skills. Retrieved from https://www.researchgate.net/publication/318740321_A_Review_of_the_Literature_on_the_Integration_of_Tec hnology_into_the_Learning_and_Teaching_of_English_Language_Skills

Healey, D. (2008). TESOL Technology Standards Framework. Virginia: Teachers of English to Speakers of Other Language.

Kapezovich, K. G., \& Toktarbekovna, D. T. (2014). E-Learning in the system of the pedagogical education in Kazakhstan. Procedia-Social and Behavioral Sciences, 152, 179-183. 
Kennedy, S., \& Soifer, D. (2013). Technology-driven innovations for teaching English learners. VA: Lexington Institute.

Kimwise, A., Mugabirwe, B. (2018). A Literature Review on Acceptance of Multimedia Technologies to Enhance E-learning in Higher Education Institutions; Focusing on Challenges. https://www.researchgate.net/publication/329034174_A_Literature_Review_on_Acceptance_of_Multimedia_Te chnologies_to_Enhance_E-learning_in_Higher_Education_Institutions_Focusing_on_Challenges

Kobysia, V. M., Zarichanska, N. V. \& Bobliienko, O. P. (2017). Creating and using electronic textbooks for language learning. Information Technologies and Learning Tools, 61(5), 15-23.

Kunanbayeva S. S. (2000). Methodical preparation of students in the conditions of informatization of the theory and methods of foreign language teaching. Almaty.

Lam, Y., \& Lawrence, G. (2002). Teacher-student role redefinition during a computer-based second language project: Are computers catalysts for empowering change? Computer Assisted Language Learning, 15(3), 295315. https://doi.org/10.1076/call.15.3.295.8185

Miner, T. (2004). Using technology to enhance learning: Instructor-or student-moderated discussion boards: Which are more effective? Retrieved from http://www.cccone.org/scholars/0405/TomMiner_final_report.pdf

Motteram, G. (2013). Innovations in learning technologies for English language teaching. British Council.

Myamesheva, G. (2015). The virtue in the modern smart world. Bulletin KazNU. Pedagogical Science Series, 1(44), 152-157.

Nayef, B. H. (2015). The advantages and disadvantages of using multimedia in education. Journal Of AL-Turath University College, 2(19), 96-104.

Nurgalieva G. K. (2002). Pedagogical technologies of informatization of education. Almaty.

Popov A.I. (1987). Review of computer training programs on foreign languages. "Methods teaching foreign languages». Minsk, 48-51 p.

Rogova G. V., Rabinovich F. M., Sakharova I. E. (1991). Methods of teaching foreign languages in secondary school. Moscow.

Solanki, D., \& Shyamlee1, M. P. (2012). Use of technology in English language teaching and learning: An analysis. International Conference on Language, Medias and Culture IPEDR vol. 33(2012)@(2012) IACSIT Press, Singapore. 150-156.

Thamarana, S. (2015). Role of Multimedia Resources in Teaching and Learning of English Language. Teaching English Language and Literature: Challenges and Solutions, 187-192.

Thamarana, S., Kumar, S., Prabhakar, T., Gulivindala, S., Matta, V., Seela, C. R., \& Ramana, P. (2015). Use of multimedia technologies in english language learning: a study. Journal of English Language and Literature, 3(3), 537-541.

Timucin, M. (2006). Implementing CALL in the EFL context. ELT Journal, 60(3), 262-271. https://doi.org/10.1093/elt/ccl006

Young, C. A., \& Bush, J. (2004). Teaching the English language arts with technology: A critical approach and pedagogical framework. Contemporary Issues in Technology and Teacher Education, 4(1), 1-22.

Zhusubalieva D.M. (1977). Theoretical bases of formation information culture of students in terms of distance learning training: Dissertation: 13.00.01. Almaty 